DOI: 10.22616/foodbalt.2017.040

\title{
USED FOOD OILS: PHYSICAL-CHEMICAL INDICATORS OF QUALITY DEGRADATION
}

Cristina Maria Carruco Laranjeira*, Claudia Sofia Escalhorda Ventura, Sara Margarida Concruta Sanchez Bermejo, Sara Pinto Teixeira Abreu dos Santos, Maria Fernanda da Silva Pires Ribeiro, Maria Gabriela de Oliveira Lima Basto de Lima, Marília Oliveira Inacio Henriques

Department of Food Technology Biotechnology and Nutrition, ESAS - Superior School of Agriculture, Polytechnic Institute of Santarem, Quinta do Galinheiro, Santarém,Portugal, e-mail: cristina.laranjeira@esa.ipsantarem.pt

\begin{abstract}
Used food oil (UFO), designated as frying oil, is a residue. Degradation by reuse or during storage, may occur by contacting, chemical, enzymatic and microbiological pathways, but oxidation is a major concern of the industry, as it affects sensory and nutritional quality of edible oils, with potentially toxic compounds formation. In Portugal, UFO's main destination still is the sewerage system, an environmental problem and waste of raw material, which can be re-qualified for non-food uses. However, quality control applied to UFO's, often results into expensive analysis inappropriate for small laboratories and catering industry. This project, developed with the Musketeers Group Portugal co-promotion (2012-2016), aimed to identify low-cost physicochemical parameters for further implementation as UFO's Quality Degradation Indicators (QDI) indicating defects quickly and accurately. UFO's analysis was tested on the use, for industrial frying, and by degradation induced in the laboratory (frying and heat stability tests) by applying following parameters: moisture, water activity (aw), total acidity, peroxide index, iodine index, colour (CIE, CIE Lab), UV absorbency, total polar compounds and microbiological indicators. Internal procedures (ESAS) were validated, redefining working ranges and test conditions, as standards procedures did not provide reliable results for the entire life cycle of oils, whose profile changes with time and reuse. Results demonstrate significant differences with quick response parameters as Total Acidity, Peroxide Index and CIE Lab colour, outlined as QDI's. Moisture, aw and CIE Lab colour proved to be inadequate for this purpose. Iodine Index and UV Absorbency are more complex and time-consuming and were profiled as reference methods.
\end{abstract}

Keywords: used edible oil, quality degradation, physical-chemical indicators.

\section{Introduction}

Food grade oils designate commercial mixtures of two or more edible oils of unlabelled variety, refined separately or together (DL 106 / 2005). For a healthy diet World Health Organization (WHO) has been established that $30 \%$ of energy consumption should originate from vegetable oils and fats (Pitts et al., 2007). Yet industrialization and changes in lifestyle leaded to an increase in its use since frying is a fast and economical culinary process of great acceptance, but is also associated with negative aspects, as higher prevalence of obesity and cardiovascular diseases (Saguy, Dana, 2003). Physicochemical changes during processing, storage and use as means of heat transfer, causes changes in its chemical profile, a spontaneous irreversible process that affects its economical and nutritional value and food safety (Gupta et al., 2004). Lipid degradation induced by frying process and reuse or during long term or inadequate storage leading to oil rancidity, may occur by contacting (with prooxidants or rancid materials), chemical, enzymatic and microbiological pathways. Oxidation is probably the best known and studied process of degradation (Silva et al., 1998); it is a major economic concern of the industry, as it affects sensory (off flavours, browning, viscosity changes, foam) and nutritional quality of edible oils, with potentially toxic compounds formation (Aladedunye, Przybylski, 2011), like acrolein, ubiquitously present in cooked foods and environment (Moghe et al., 2015). In frying process, oil interacts with air, water and other food components, undergoing a complex chemical process of degradation by chain reactions, which affects the triacylglycerol molecules by hydrolysis and oxidation (Takeoka et al., 1997), the latter through a radical mechanism involving oxygen singlet $\left({ }^{1} \mathrm{O}\right)$, resulting into peroxidation (primary oxidation) and subsequently, fission, polymerization, condensation, interesterification, cyclization, etc. (terminal reactions or secondary oxidation) (Sahin, Sumnu, 2009), with the increase of free fatty acids, carbonyl groups, conjugated dienes and polymeric compounds (Gupta et al., 2004). Temperature, light, pressure, moisture, enzymes, metal ions, influence the radical mechanism and the final products profile (White, 2006). In continuous industrial frying, food is completely submerged and the process is not interrupted, but in homemade frying and restoration a discontinuous process is used; the oil is heated at high temperatures $\left(150-180^{\circ} \mathrm{C}\right)$ and subjected to temperature cycles and different types of food, being successively cooled and reheated, accelerating its degradation (Choe, Min, 2007). Used Food Oil (UFO) is a residue (DL 267 / 2009). In Portugal, although collection is mandatory - resulting into untraceable oil mixtures UFO's main destination still is the sewerage system, an environmental problem and waste of valuable raw material in production of biodiesel, soap composting, etc. Estimated annual production is of $43000 \mathrm{t}$ to 65000 $\mathrm{t}$, generated by domestic sector $(62 \%)$, hotel and catering sector $(37 \%)$ and a residual fraction from food industry (IGAOT, 2005). Edible oil's analysis highlights quality ensuring its authenticity and safety; yet, when applied to UFO's intended for non-food recovery, often resorts into inappropriate expensive analysis, pointing to the convenience of further research focused on those degraded oils.

The present research, whose experimental period spanned two biennia, 2012-2013 and 2014-2015, aimed to identify low-cost physicochemical parameters enabling to detect incipient and severe degraded oils, for 
further implementation as UFO's. Quality Degradation Indicators (QDI) indicating defects, inexpensively, accurately and quickly. Experimental Design. Oils were subjected to real or induced degradation, by industrial frying or laboratory scale equipment (e.g. frying and heat stability tests) performed under use and abuse conditions. Oil's analysis was tested on the use by applying following parameters: moisture content $(\% \mathrm{H})$, $\mathrm{a}_{\mathrm{w}}$, total acidity (AT), peroxide index (IP), iodine index (II), colour (CIE and CIE Lab) and UV absorbency (AbsUV), all common and feasible in small laboratories. Monitoring was done by microbiological control and later on (2014-15), also by total polar compounds' (TPC) rapid method. TPC value corresponds approximately to the total change of compounds formed during frying. TPC's colorimetric quick tests are inexpensive kits alternative to chromatographic standard method (not suitable for a small industry or vendor to use on site), allowing reliable response in minutes without specialized personnel (Chen at al., 2012). Used in restoration and by official entities, they remain unchanged allowing use as legal evidence. Portuguese regulations (Ordinance 1135/95) states maximum permissible limit for TPC in foods prepared in oils as $25 \%(\mathrm{w} / \mathrm{w})$. Heat stability and fry tests (in 2014-2015), aimed to provide complementary data to the untraced real-use UFO's (analysed in 2012-2013), using equivalent techniques, but by being performed in a laboratory environment may be controlled and verified, also providing oil's samples usable as internal patterns.

\section{Materials and Methods}

Samples

All came from the Musketeers Group Portugal facilities, in Alcanena. Sampling intended to cover an extended food oil's use. New food grade oils were delivered in sealed plastic bottles $\left(1 \mathrm{dm}^{3}\right)$ of the trade mark partnersupplied (Bouton d'Or): 3 units (2012), 6 (2013) and 12 (2014-2015), having the same lot code in each delivery phase. UFO's were provided in plastic containers $\left(5 \mathrm{dm}^{3}\right)$. First trial of indicators (2012), were performed with just 3 samples: new (OAN), twice used $\left(\mathrm{OAU}_{2 \mathrm{x}}\right)$, and rejected oil from Alcanena's base (OAUr). In $2^{\text {nd }}$ phase (2013), 14 samples of untraced UFO (encoded A to N) were provided, having different degrees of sensory perceptible degradation. The first heat stability test was also conducted (2013) using new oil (OS); samples were taken at $\mathrm{i}=0,1,2,4,6$ and $8^{\text {th }}$ weeks in a drying chamber (collecting triplicates of 3 independent units - j, samples totalling 18 (OSij). To microbiological first tests (2012-2013), 3 other samples were specifically provided: new oil (O1) and two UFO's (O2, O3) collected in sterile package both degraded (turbid and brownish). In the last phase of experiments (2014-15), frying tests were performed by immersion of potato and nuggets in heated oils (OFB, OFN, respectively); new oil samples were successively reused and collected at $\mathrm{i}=0,2,5,10,15,20$ and $25^{\text {th }}$ fry. Four experiments were done, generating 28 different samples (OFBi, OFNi). A $2^{\text {nd }}$ heat stability test was also carried out with new oil (OE), extending time up to 14 weeks in the oven, collecting combined samples every two weeks, totalling 8 (OEi). All 71 samples obtained during the project were submitted to physicalchemical analysis, and most degraded also to microbiological tests. In analytical assays, number of replicates was standardized under repeatability conditions: five for microbiological and CIE Lab colour (2012-15), ten (2012, for validation purposes) and later on three (2013-15) for all other physicochemical parameters.

\section{Heat stability and fry tests}

Heat stability tests (ST) were designed as a forced (accelerated) shelf life test. A convective drying electrical chamber (Memmert, Model 40050 IP20), operated at constant temperature of $39{ }^{\circ} \mathrm{C}$, was used. Food oils have a shelf life of 18 months, but 1 week in an electric chamber at $39^{\circ} \mathrm{C}$ in closed bottle is equivalent to 2 months' oil's exposure under natural storage conditions (Industry personal communications). The test was performed twice $(2013,2015)$, held in triplicate new oil samples placed closed in the oven in their original bottles. In frying tests (FT), a domestic electric fryer of $1.5 \mathrm{dm}^{3}$ max capacity, from Moulinex, was used. Frozen commercial samples of potatoes into cubes or chicken nuggets were weighed $(150 \mathrm{~g} \pm 0.01 \mathrm{~g})$ and fried in $1.5 \mathrm{dm}^{3}$ of oil at $180{ }^{\circ} \mathrm{C}$ for 4 to 6 minutes. The oil was subjected to reuse as a frying medium for a single food (potato or nuggets), each cycle performed with or without fresh oil replacement to the $10^{\text {th }}$ operation. In each assay, total heating time was 99 min (average) and total frying time about $109 \mathrm{~min}$, being $207 \mathrm{~min}$ ( $3 \mathrm{~h} 27 \mathrm{~min}$ ) the actual mean time of use of the oil in those operations. In both ST and FT, sampling over time $\left(120 \mathrm{~cm}^{3}\right.$ each oil collection) was that described.

\section{Physical-chemical analysis}

$\% \mathrm{H}$ was determined by ISO Standard 3727-1 (2001), using a precision balance (Sartorius BI210s) and an electric oven with ventilation (Memmert 40050 IP20) at $103 \pm 2^{\circ} \mathrm{C}$. $\mathbf{a}_{\mathbf{w}}$ was measured by direct method (Rotronic, Model Hygroskop DT; Rotronic cells model DMS $100 \mathrm{H}$ ) at $25^{\circ} \mathrm{C}$, using water bath (Selecta, Model Unitronic 6320100). AT was determined by minor modification of the titration method described in the Portuguese Standard NP-903 (1987), results expressed in $\mathrm{g}_{\text {oleic acid }} 100 \mathrm{~g}^{-1}$. IP and II were determined by classical iodimetry, the first according to NP-904 (1987), results in meq-O $\mathrm{kg}^{-1}$; the last, by adapting NP-941 (1985) and results expressed in $\mathrm{g}-\mathrm{I}_{2} 100 \mathrm{~g}^{-1}$. Colour in the CIE L*a*b* space (CIE Lab) were determined using a reflectance colorimeter (Chroma Meter CR-400 by Konica Minolta, controlled by the SpectraMagic NX software), measuring the cartesian coordinates $\mathrm{L}^{*}, \mathrm{a}^{*}$, $b^{*}$, where $L^{*}$ is brightness $\left(0=\right.$ black to $100=$ white), $a^{*}$ is the green/red chromatic coordinate (negative or positive values, respectively), and $b^{*}$ is blue / yellow coordinate (negative / positive); chroma $\left(\mathrm{C}^{*}\right)$ and hue $\left(\mathrm{H}^{\mathrm{o}}\right)$, were calculated: $\mathrm{C}^{*}=\left(\mathrm{a}^{* 2}+\mathrm{b}^{* 2}\right)^{1 / 2}$ and $\mathrm{H}^{\mathrm{o}}=\tan ^{-}$ ${ }^{1}\left(\mathrm{~b}^{*} / \mathrm{a}^{*}\right)$. The instrument was standardized each time 
with a black and a white tile ( $\mathrm{Y}=89.5 ; \mathrm{x}=0.3176$; $\mathrm{y}=0.3347$ ) using D65 illuminate and a $2^{\circ}$ observer. CIE colour was determined by absorbance at 445, 495, 560 and $625 \mathrm{~nm}$ against carbon tetrachloride referred to the $1 \mathrm{~cm}$ thickness, using a UV-Vis spectrophotometer (Hitachi, Model U-2001); internal procedure was adapted from NP 937 (1987). Apparent and real colour was determined in the original and centrifuged (3000 rpm, $30 \mathrm{~min}$ ) samples, respectively; stimuli X, Y, $\mathrm{Z}$, was calculated to determine CIE attributes: dominant wavelength $(\lambda)$, purity $(\sigma)$, transparency $(Y)$ and $\operatorname{Tg} \alpha$ value. AbsUV allows detection of conjugated dienes, absorbing at 230-235 nm, as also conjugated trienes and oxidation by-products at 260, 270 and $280 \mathrm{~nm}$ (Wan, 2000). Absorbance was measured against isooctane at $232 \mathrm{~nm}$ and 264-272 nm, expressed as absorbance coefficients $\mathrm{K}_{232}, \mathrm{~K}_{268}$ and $\Delta_{268}$, referred to $1 \mathrm{~g}_{\text {oil }} 100 \mathrm{~cm}^{-3}$ and $1 \mathrm{~cm}$ thickness, according to NP 970 (1986). Actual measures were performed in diluted oil solutions $(1: 5,1: 10,1: 25)$ after the originals $\left(1 \mathrm{~g} 100 \mathrm{~cm}^{-3}\right)$, to allow readings in the $0.2-2.0$ absorbance range. UV-Vis spectrophotometer (Hitachi U-2001) was used. Internal procedures were validated to repeatability (2012), redefining test conditions and working ranges. Relacre (2000) recommendations were used as validation criteria. In previous trials, oil samples $\left(\mathrm{OAN}, \mathrm{OAU}_{2 \mathrm{x}}, \mathrm{OAUr}\right)$ were used to calculate the coefficients of variation of repeatability $(\mathrm{CVr})$, comparing mean values to the respective standard deviations using its percentage ratio; results leaded to acceptable values $(\mathrm{CVr}<5-10 \%)$ for all physicalchemical indicators except for $\% \mathrm{H}, \mathrm{a}_{\mathrm{w}}$ and CIE apparent colour, due to its highly dispersive results (Laranjeira et al., unpublished data). ST and FT were monitored by TPC using a colorimetric kit (FRITEST®). Numeric scale associates state of the oil to colour response: 1 - good, 2 - still good, 3 - replace, 4 - bad.

\section{Microbiological analysis}

Degradation of oils by microbial means is rare, as they are practically water free. However, lipid flora may be responsible for OAU's rancidity since they incorporate water through food. Enumeration of lipolytic microorganisms was performed according to Bourgeois, Leveau (1991), using Tributyrine Agar. Lipolytic fungi enumeration was similar, but to Tributyrine Agar medium was added chloramphenicol; xerophilic fungi enumeration was done according to the NFV Standard 08036 (2003) using Dicloran-Glycerol Chloramphenicol Agar medium.

\section{Statistical analysis}

Physicochemical data was analysed with a one-way ANOVA and mean values were compared using Post Hoc LSD Tuchey's Unequal test, except for CIE colour (2013) and for all mean values of FT parameters, as they were compared using Post Hoc LSD Ficher test, considering two independent variables "sample" and "treatment". Also for ST assays both tests were used, since it was intended to isolate the "bottle / position" effect (2013), but in the $2^{\text {nd }}$ series (2015), composite samples were prepared. For treatment of multivariate data, Principal Component Analysis (PCA) was used. In all tests a level of significance of $95 \%(\mathrm{p}<0.05)$ was considered (Wilks test) and the software used was Statistica version 7.0 (Stat Soft Inc.) for Windows.

\section{Results and Discussion}

It is intended to report most significant results due to screening also highlighting PI and colour data, providing brief information on other parameters in order to allow the understanding of results obtained by TPC analysis. In previous tests (2012), moisture $(\% \mathrm{H})$ revealed a poor performance as QDI. It was observed (Laranjeira et al., 2014) a clear distinction in drying needs: the more degraded the oil, the longer the time required. In final assays both new $(\mathrm{OAN})$ and twice used $\left(\mathrm{UFO}_{2 \mathrm{x}}\right)$ oils were submitted to initial 60 min drying at $103 \pm 2{ }^{\circ} \mathrm{C}$, followed by periods of 15 min extending up to 105 min drying. Oils reached constant weight at 60 $\min (\mathrm{OAN})$ and $75 \mathrm{~min}\left(\mathrm{UFO}_{2 \mathrm{x}}\right)$ and despite high dispersion, recorded minimum (w.b) moisture of $0.044 \pm 0.050 \%$ and $0.068 \pm 0.021 \%$, respectively. From this point, samples registered mass increase. Degraded OAUr were submitted to initial $240 \mathrm{~min}(4 \mathrm{~h})$ drying, followed by periods of $30 \mathrm{~min}$, total time drying being $360 \mathrm{~min}(6 \mathrm{~h})$; consistent mass loss were recorded during the first 5 hours $(300 \mathrm{~min})$ minimum corresponding to $0.036 \pm 0.050 \%$ (w.b.) moisture. This lowest result, suggests a later prevalence of water loss by evaporation and hydrolysis (AT is also higher) in relation to its incorporation from food in a large frying reuse. Inversion in oil's drying curves with mass increased is associated to oxidation (Harpern, 1997). Drying may require a long time run, drying time is not predictable in advance for all UFO and results are low precision, which renders the method uninteresting. $a_{w}$ was also eliminated in late 2013 as no significant differences between UFO's samples (OAN, OAU $2 \mathrm{x}$, OAUr and oil's A to $\mathrm{N}$ ) where observed: measures between $0.5403 \pm 0.0006$ minimum $(\mathrm{E})$ and $0.73 \pm 0.14$ maximum (I), led to unsatisfactory highly dispersed results, though data were probably compromised by the inadequacy of equipment: slow and low sensitivity instrumental response for lipid matrices besides non-airconditioned laboratory (Laranjeira et al., 2014 and unpublished data). CIE and CIE Lab colour were determined in UFO's samples. CIE is the standard and allows determination of apparent and real colour, unlike CIE Lab. CIE system was appealing only because in frying practise, oils are not centrifuged, allowing a closer observation of the real state of the on-the-use oils. Table 1 shows the CIE colour results (means and standard deviations) obtained in 2012 exploratory tests, presenting $\lambda$ (dominant wavelength), $\mathrm{Y}$ and $\sigma$ parameters, where $(\mathrm{O})$ refer the original and $(\mathrm{C})$ the centrifuged oil's samples. Oil not only dim, but the reflected spectral radiation becomes more yellow $(\lambda)$ and monochromatic $(\sigma)$ with degradation. $Y$ is significantly lower in OAUr yet higher in centrifuged samples, as expected. 
Table 1

Real and apparent CIE colour parameters

\begin{tabular}{lccc}
\hline $\begin{array}{l}\text { Oil } \\
\text { samples }\end{array}$ & $\boldsymbol{\lambda}, \mathbf{n m}$ & $\boldsymbol{\sigma}, \boldsymbol{\%}$ & $\mathbf{Y}, \boldsymbol{\%}$ \\
\hline OANC $_{C}$ & $571.52^{\mathrm{c}} \pm 0.17$ & $5.96^{\mathrm{c}} \pm 0.04$ & $94.34^{\mathrm{b}} \pm 0.09$ \\
OANO $^{\mathrm{a}}$ & $572.87^{\mathrm{e}} \pm 0.33$ & $4.62^{\mathrm{a}} \pm 0.06$ & $89.72^{\mathrm{d}} \pm 0.18$ \\
OAU $_{2 \times C}$ & $571.97^{\mathrm{b}} \pm 0.15$ & $5.52^{\mathrm{b}} \pm 0.10$ & $94.44^{\mathrm{b}} \pm 2.41$ \\
OAU $_{2 \times 0}$ & $570.88^{\mathrm{d}} \pm 0.55$ & $4.52^{\mathrm{a}} \pm 0.38$ & $84.34^{\mathrm{a}} \pm 0.11$ \\
OAUrC & $574.17^{\mathrm{a}} \pm 0.03$ & $44.33^{\mathrm{d}} \pm 0.21$ & $83.81^{\mathrm{a}} \pm 0.85$ \\
OAUrO & $574.03^{\mathrm{a}} \pm 0.13$ & $44.90^{\mathrm{e}} \pm 0.15$ & $76.45^{\mathrm{c}} \pm 0.27$ \\
\hline
\end{tabular}

However, CIE colour is a costly, laborious, reagent dependent technique, uninteresting as QDI and CIE Lab system is a simpler and eco-friendly method. Experiments were repeated with UFO's A to N, aiming to evaluate the replacement of CIE by CIE Lab system, in used oils. Those 14 untraceable oils led to more scattered results (Laranjeira et al., unpublished data), but data were compared by TPC (Fig 1).

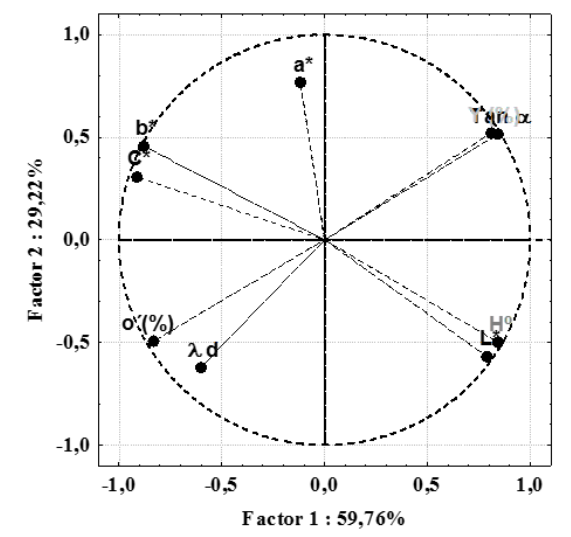

Figure 1. TPC's variable projection in the plan for used food oils A to N - CIE and CIE Lab colour

Strongest correlations are between internal parameters of CIE or CIE Lab, but factors 1 and 2 evidence correlations between the systems. To this end, it was decided to discontinue the CIE colour assays. Figure 2 presents the results for b* with UFO's A-N series. Data is presented as a curve to evidence randomness, but these are discrete points of distinctive oils, internally ordered by increasing degradation based on results of classical parameters, AT, IP and II and sensory evaluation. Frying oil's colour depends mostly on its composition, refining conditions and use. An increase in $b^{*}$ value (yellow) as oil degrades has been reported, due to photo and thermal oxidation. Isomerization of double bonds leads to greater absorbance of blue light, with an increase of colour in the orange and brown hues (Choe et al., 2007); polymerization and absorption of dark pigments from food to oil, due to Maillard reactions, also contribute (Gunstone, 2008).

Yet, instead of presenting progress with re-frying, curve (Fig. 2) suggest the influence of individual matrices of different untraced oils on the dispersion of $b^{*}$ values the same behaviour was observed with other colour parameters and in AbsUV (Laranjeira et al., unpublished data) - as, likely different colour (or UV absorbency) in original (blend) oil's lots, shelf life, unknown conditions of storage and use, and others, as those related to techniques, e.g. instrumental error.

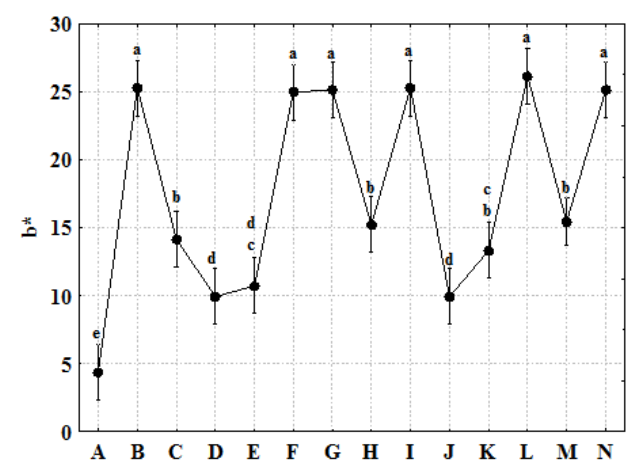

Figure 2. CIE Lab coordinate $b^{*}$ for used food oils

Despite randomness, $b^{*}$ value tends to increase from new (A) to degraded (N) oil; this trend was confirmed by the results of FT and ST, where significant differences were observed along re-frying or heat exposure by ANOVA and TPC analysis. Mean values with different superscript letters are significantly different $(\mathrm{p}<0.05)$. In ST $(2015), b^{*}$ value increased regularly along permanence in the electric chamber, being $4.59^{\mathrm{b}} \pm 1.33(\mathrm{~min})$ in the original oil $(\mathrm{OE})$ and $22.65^{\mathrm{e}} \pm 2.62(\max )$ on the $14^{\text {th }}$ week; in 2013 , values were $4.53^{\mathrm{a}} \pm 0.17(\mathrm{~min})$ in the original (OS) up to $15.62^{\mathrm{h}} \pm 0.68(\max )$ at the $8^{\text {th }}$ week. In potato frying assays, without oil replacement $(\mathrm{S}), \mathrm{b}^{*}$ also increased from $5.44^{\mathrm{a}} \pm 2.38$ in new oil (OFB) to $54.92^{\mathrm{f}} \pm 1.80$ after the $25^{\text {th }}$ fry; in fry with oil replacement to the $10^{\text {th }}$ reuse (assay C) - where maximum was observed $\left(29.14^{\mathrm{d}} \pm 2.11\right)-\mathrm{b}^{*}$ decreased by the $15^{\text {th }}$ reuse to $5.99^{\mathrm{a}} \pm 0.01$ returning to maximum at the $25^{\mathrm{h}}$ fry $\left(29.18^{\mathrm{d}} \pm 3.08\right)$, suggesting degradation by contacting fresh and used oils. In experiments with nuggets, variation of the yellow colour was higher and the effect of replenishment was not observed; $b^{*}$ values always increased with reuse: from $5.88^{\mathrm{a}} \pm 1.09$ in new oil (OFN) to $79.32^{\mathrm{i}} \pm 1.76$ (assay $\mathrm{S}$ ) and up to $71.89^{\mathrm{h}} \pm 3.64$ (assay C), respectively, in $25^{\text {th }}$ fry. In all studies, progress of chroma $\left(\mathrm{C}^{*}\right)$ were very similar to the corresponding coordinate $\mathrm{b}^{*}$, but lightness $\left(\mathrm{L}^{*}\right), \mathrm{a}^{*}$ (green, negative) and hue $\left(\mathrm{H}^{\circ}\right)$ data, was characterized by some dispersion, higher in the UFO's series. FT and ST results indicated differences of relatively small magnitude in progress (although often statistically significant) and the evolution of the curves, were close to a steady model, with oscillations around mean value.

Table 2

CIE Lab’s principal data in oils assays

\begin{tabular}{lccc}
\hline Variable & $\begin{array}{c}\text { Mean } \\
\text { (combined) }\end{array}$ & Max & Min \\
\hline $\mathrm{L}^{*}$ & $60.8 \pm 9.1$ & $94.9 \pm 0.3^{1}$ & $46.8 \pm 1.0^{2}$ \\
$\mathrm{a}^{*}$ & $-6.9 \pm 7.3$ & $-0.6 \pm 0.4^{3}$ & $-24.6 \pm 0.3^{4}$ \\
$\mathrm{~b}^{*}$ & $20.7 \pm 19.3$ & $79.3 \pm 1.8^{4}$ & $1.7 \pm 1.6^{5}$ \\
$\mathrm{C}^{*}$ & $22.3 \pm 20.3$ & $83.1 \pm 1.6^{4}$ & $2.8 \pm 0.9^{3}$ \\
$\mathrm{H}^{\mathrm{o}}$ & $108.7 \pm 11.3$ & $168.2 \pm 10.7^{5}$ & $94.46 \pm 0.3^{6}$ \\
\hline
\end{tabular}

Oil samples: 1 - OAN, 2 - OFB2, 3 - OE2, 4 - OFN25-S, 5 - OE10, 6 - I 
Table 2 presents a short compilation of data obtained with the 71 oil samples universe.

Classical parameters AT, IP and to a lesser extent, II, gave the most regular and predictable data in the set of all tests, the shape of the curve with oil's degradation being very similar, in its respective parameters, in all experiments (Laranjeira et al., unpublished data). Peroxide index (IP), the most common parameter used to characterize oils and fats presented a Gaussian evolution, decreasing when the secondary oxidation products appear as noticed by Silva et al. (1998) and Chen at al. (2012). As an example, Figure 3 shows IP curves based on the results of nuggets frying assays and its monitoring by TPC.

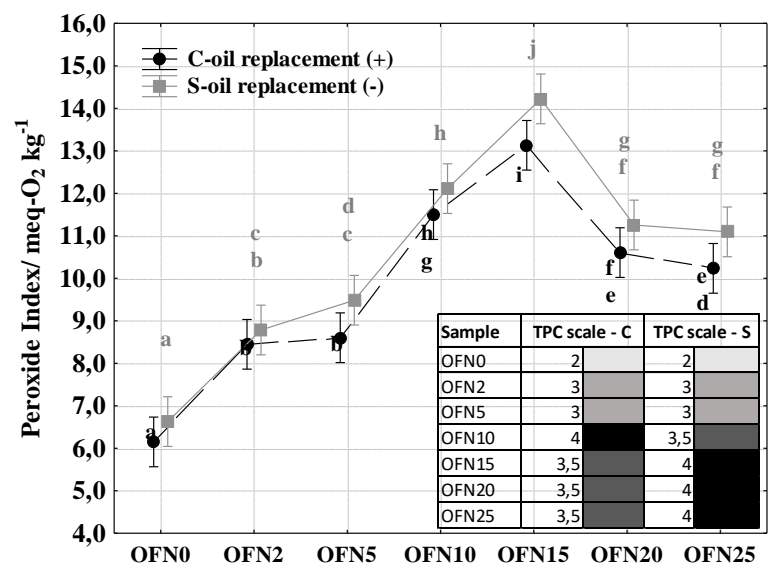

Figure 3. IP and TPC values in nuggets frying assay TPC's oil scale: 1-good, 2-still good, 3-replace, 4-bad.

In frying oil's group, recommended maximum limit of 15 meq-O $\mathrm{Og}_{2}^{-1}$ (Moigradean et al., 2012) was not exceeded (with one exception), being the absolute maximum of $13.03 \pm 0.26$ in potato's frying $\left(\mathrm{OFB} 10,10^{\text {th }}\right.$ fry, TPC value: $4-b a d)$, and $10.30 \pm 0.28$ (G) and $37.55 \pm 0.37\left(\mathrm{OAU}_{2 \mathrm{x}}\right)$ in UFO's series. It was also overpass in first ST: $34.86 \pm 0.28$ (OS8, $8^{\text {th }}$ week), but not in the $2^{\text {nd }}, 12.78 \pm 0.25$ (OE6, $6^{\text {th }}$ week) where TPC colour test remained unchanged (1-good) during assay. The lowest IP values registered with the most degraded oils were similar (no significant differences) to those of new oil, being $1.99 \pm 0.42(\mathrm{~N}), 3.71 \pm 0.26$ (OAUr), 5.30 \pm 0.28 (OE14, $14^{\text {th }}$ week) and 10.23 \pm 0.29 (OFB25-S, 25 ${ }^{\text {th }}$ fry). The highest and lowest IP values in

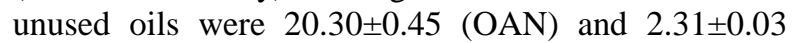
(OFB). Highest TPC' recorded value for unused oil was 2-still good (OFN) (Fig. 3). In Total acidity (AT), related to hydrolysis, samples quickly acidified with the first two fried, and later, in most degraded oils. Lowest (initial) and highest (final) values obtained were $0.0067 \pm 0.0010$ (OFB) and $0.317 \pm 0.012$ (OAUr) in $\mathrm{g}_{\text {oleic }}$ acid $100 \mathrm{~g}^{-1}$, respectively. In low-medium degraded oils (present in UFO' series and induced lab tests) - where TPC' values were 1 -good to 3 - replace none or minor significant differences were registered. Iodine index (II) not being Gaussian, actually presented an initial increase in values, due to nonspecific iodization reactions (Ricardo, Teixeira, 1988) giving a more accurate response regarding (secondary) oxidation with the most degraded frying oils, where II declines with increasing degradation (Laranjeira et al., unpublished data). The highest and lowest II values, in $\mathrm{g}-\mathrm{I}_{2} 100 \mathrm{~g}^{-1}$, on unused oils were $38.12 \pm 0.40(\mathrm{OAN})$ and $34.727 \pm 0.060$ (A), being of 37.080 \pm 0.076 (OE14) and $19.18 \pm 0.15$ (OAUr) for degraded oils, respectively. In ST assays minor changes were observed. UV's absorbance coefficient $\mathrm{K}_{232}$ that undergone a Gaussian evolution, closely related to IP; highest, lowest and mean values were $37.86 \pm 0.52\left(\mathrm{OAU}_{2 \mathrm{x}}\right), 0.00 \pm 0.26$ (OFB) and $10.7 \pm 5.2$ respectively. $\mathrm{K}_{268}$, associated to secondary oxidation, had a less predictable, random progress; highest, lowest and mean values were $9.21^{\mathrm{i}} \pm 0.26$ (OFN5), $0.77^{\mathrm{a}} \pm 0.05(\mathrm{OFN})$ and $3.1 \pm 2.5 . \Delta_{268}$ registered minor or no significant differences in all assays, its combined mean being 0.29 \pm 0.41 . Microbiological tests held positive results in oils $\mathrm{O} 2$, O3, C, D, G, I, L, N, OFBi and OFNi (i=15, 20, 25); highest enumerations were: $1.8 \times 10^{3}$ c.f.u. $\mathrm{dm}^{-3}$ for lipolytic microorganisms (OFB20-C), 2 (OFB25-S) and 3 (I) c.f.u. $\mathrm{dm}^{-3}$ for xerophilic and for lipolytic fungi. All physicochemical parameters outlined as indicators were treated by TPC. Table 3 and Figure 4 show variables and case's projection in the plan, considering all 71 samples.

Table 3

TPC - Principal components for used oils

\begin{tabular}{lccc}
\hline \multirow{2}{*}{ Variables } & Factor 1 & Factor 2 & Factor 3 \\
\cline { 2 - 4 } & $\mathbf{4 1 . 0 7 3 6 0 \%}$ & $\mathbf{1 9 . 6 4 4 2 0 \%}$ & $\mathbf{1 6 . 9 0 6 6 3 \%}$ \\
\hline IP & -0.069032 & $\mathbf{- 0 . 8 1 4 2 5 7}$ & 0.242260 \\
II & 0.216178 & -0.131070 & $\mathbf{0 . 8 4 8 6 1 6}$ \\
AT & $\mathbf{- 0 . 6 6 1 2 6 6}$ & -0.165999 & -0.458827 \\
b* & $\mathbf{- 0 . 8 9 3 1 3 1}$ & 0.302022 & 0.177146 \\
C $^{*}$ & $\mathbf{- 0 . 8 9 8 0 3 1}$ & 0.263761 & 0.210018 \\
K $_{232}$ & -0.473889 & $\mathbf{- 0 . 7 1 0 4 1 2}$ & -0.191190 \\
$\mathrm{~K}_{268}$ & $\mathbf{- 0 . 7 4 6 7 6 7}$ & -0.043268 & 0.286461 \\
\hline
\end{tabular}

The distribution of variables by principal components is consistent with the phenomena they indicate and, despite a large overlap in the projection of cases, sample grouping reflect clockwise trend with the increasing oil's degradation. Groups 1 to 3 join usable oils (new and ST samples). UFO and FT samples are in groups $4-5$, the latter linking visually deteriorated and almost all oils used in frying nuggets.

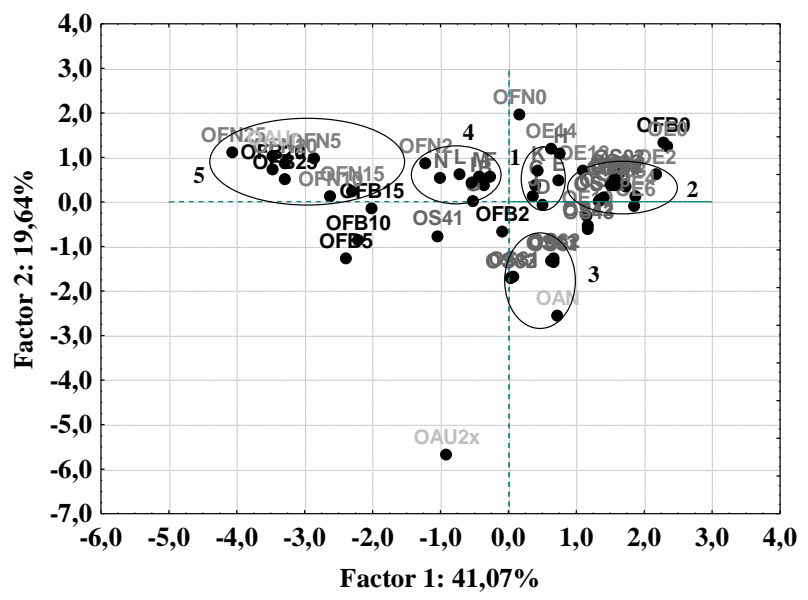

Figure 5. TPC's sample projection in the plan 
Peroxidation indexes (IP, $\mathrm{K}_{232}$ ) are strongly correlated, like CIE Lab coordinates $b^{*}$ and $C^{*}$ (coordinate $a^{*}$ is mostly stationary), AT and $\mathrm{K}_{268}$. These parameters have a major influence in groups 1 and 2 as in ungrouped samples ( $3^{\text {rd }}$ quadrant). II, being the least specific and most isolated, still contributes to the positioning of samples of the $2^{\text {nd }}$ quadrant and also to most degraded ones ( $4^{\text {th }}$ quadrant); in this last case, II progress is negative (specific for oxidation) and $\mathrm{b}^{*}$ and $\mathrm{C}^{*}$ are major important variables. $\mathrm{OAU}_{2 \mathrm{x}}$ atypical and isolated, with low use in frying $(2 \mathrm{x})$ but a moderate depreciation and strongly associated with IP, suggests degradation upstream of the use, probably due to poor storage or senescence by long shelf life of the original oil before frying use.

\section{Conclusions}

Frying oils incorporate products of its degradation, externals and water affecting related parameters $\% \mathrm{H}, \mathrm{a}_{\mathrm{w}}$ and AT and indirectly, oxidation indicators (Chen et al., 2012). TPC, IP, II, CIE and CIE Lab colour and AbsUV are associated with oxidative effects. Each method provides only partial information on oil's degradation (Silva et al, 1998), but CIE system, \%H and $\mathrm{a}_{\mathrm{w}}$ was, to this end, inadequate. TPC analysis showed correlations in the remaining parameters, suggesting different possible choices in distinct phases of the oil life cycle. TPC signals earlier degradation (in the FT, not in ST assays), recommending oil's replacement before other parameters show clearly significant changes. Yet, considering the requirements, results suggests that AT, IP and CIE Lab colour (b*, C*) are suitable as Quality Degradation Indicators for UFO intended for non-food recovery. AbsUV, and to a lesser extent, II, both more complex and time-consuming, are outlined as complementary, reference methods.

\section{Acknowledgment}

The authors acknowledge the sponsor of The Musketeers Group Portugal.

\section{References}

1. Aladedunye F., Przybylski R. (2011) Frying performance of canola oil triacylglycerides as affected by vegetable oils minor components. Journal of the American Oil Chemists' Society, Vol.89, p. 1-13.

2. Bourgeois C.M., Leveau J.Y. (1991) Techniques d' Analyse et de Contrôle dans les Industries Agro Alimentaires. Collection Sciences et Techniques Agroalimentaires. Vol. 4. 2nd ed. ed. J.F. Multon. Paris: Lavoisier, p. 343-345.

3. Chen W.A., Chiu C.P., Cheng W.C., Hsu C.K., Kuo M.I. (2012) Total polar compounds and acid values of repeatedly used frying oils measured by standard and rapid methods. Journal of Food and Drug Analysis, Vol. 21, p. 58-65.
4. Choe E., Min D.B. (2007) Chemistry of deep-fat frying oils. Journal of Food Science, Vol. 5 (7), p. 77-86.

5. DL 106/2005 [Dec-Law]. Diário da República, No 123. (in Portuguese)

6. DL 276/2009 [Dec-Law]. Diário da República, No 189 (in Portuguese)

7. Gunstone F.D. (2008) Oils and Fats in the Food Industry. Wiley-Blackwell. $160 \mathrm{p}$.

8. Gupta M, Warner K, White P. (2004) Frying Technology and Practices. 2nd ed. Illinois: AOCS Press. $231 \mathrm{p}$.

9. Halpern M.J. (1997) Bioquímica. Lisboa; Lidel. 622 p.

10. IGAOT (2005). Temática dos óleos alimentares usados. Working paper. [Accessed on 11.10.2016.]. Available: http://www.netresiduos.com/Handlers/FileHandler.ashx?i $\mathrm{d}=766$ \& menuid $=224$

11. Laranjeira C., Ribeiro M., Henriques M., Bermejo S. (2014) Óleos alimentares usados: selecção de indicadores de degradação de qualidade. Revista da UIIPS. [Used food oils: selection of indicators of quality degradation Vol. 4 (2), p. 163-181 (in Portuguese)

12. Moghe A., Ghare S., Lamoreau B., Mohammad M., Barve S., McClain C., JoshiBarve S. (2015) Molecular mechanisms of acrolein toxicity: relevance to human disease. Toxicological Sciences, Vol. 143 (2), p. 24255.

13. Moigradean D., Poiana M.A., Gogoasa I. (2012) Quality characteristics and oxidative stability of coconut oil during storage. Journal of Agroalimentary Processes and Technologies, Vol. 18 (4), p. 272-276.

14. Ordinance 1135/95. Portaria $\mathrm{n}^{\circ} 1135 / 95$ de 15 de Setembro. Diário da República - I Série-B N. ${ }^{\circ} 214$. (in Portuguese)

15. Pitts M.; Dorling D., Pattie C. (2007) Oil for food: The global story of edible lipids. Journal of World-Systems Research, Vol. 13, p. 12-32.

16. Relacre (2000) Guia RELACRE 13. Validação de Métodos de Ensaio em Análise Química. [accessed on 2.10.2016]. Available: http://www.relacre.pt. (in Portuguese)

17. Ricardo C.P.; Teixeira A.N. (1983) Moléculas Biológicas: estrutura e propriedades. Didáctica Editora: Lisboa. 277 p. (in Portuguese)

18. Saguy S., Dana D. (2003) Integrated approach to the deep fat frying: engineering, nutrition, health and consumer aspects. Journal of Food Engineering, Vol. 56, p. $143-152$.

19. Sahin S., Sumnu S.G. ed. (2009) Advances in deep-fat frying of food. New York: CRC Press. 321p.

20. Silva F.A., Borges M.F., Ferreira M. (1998).Métodos de avaliação do grau de oxidação lipídica e da capacidade antioxidante. Química Nova, Vol. 22 (1), p. 94-103. (in Portuguese)

21. Takeoka G.R.; Fuli G.H., Dao L.T. (1997) Effect of heating on the characteristics and chemical composition of selected frying oils and fats. Journal of Agricultural and Food Chemistry, Vol. 45, p. 3233-3249.

22. Wan, J.P. (2000) Properties of Fats and Oils in Introduction to Fats and Oils Technology. Illionois: AOCS Press. Champaign, p. 20-49.

23. White, J. P. (2006). Fatty Acids in Oilseeds (Vegetable Oils). In: Fatty Acids in Foods and their Health Implications. 3th ed. Ching Kuang Chow: CRC Press, p. 227-262. 